\title{
Substrate-specific transcription of the enigmatic GH61 family of the pathogenic white-rot fungus Heterobasidion irregulare during growth on lignocellulose
}

\author{
Igor Yakovlev • Gustav Vaaje-Kolstad • Ari M. Hietala • \\ Emil Stefańczyk • Halvor Solheim • \\ Carl Gunnar Fossdal
}

Received: 10 February 2012 /Revised: 21 May 2012 / Accepted: 23 May 2012 /Published online: 21 June 2012

(C) The Author(s) 2012. This article is published with open access at Springerlink.com

\begin{abstract}
The GH61 represents the most enigmatic Glycoside Hydrolase family $(\mathrm{GH})$ regarding enzymatic activity and importance in cellulose degradation. Heterobasidion irregulare is a necrotizing pathogen and white-rot fungus that causes enormous damages in conifer forests. The genome of $\mathrm{H}$. irregulare allowed identification of ten $\mathrm{HiGH61}$ genes. qRT-PCR analysis separate the HiGH61 members into two groups; one that show up regulation on lignocellulosic substrates (HiGH61A, HiGH61B, HiGH61D, $H i G H 61 G, H i G H 61 H$, and $H i G H 61 I$ ) and a second showing either down-regulation or constitutive expression (HiGH61C, HiGH61E, HiGH61F, and HiGH61J). $\mathrm{HiGH61H}$ showed up to 17,000 -fold increase on spruce heartwood suggesting a pivotal role in cellulose decomposition during saprotrophic growth. Sequence analysis of these genes reveals that all GH61s except $H i G H 61 G$ possess the conserved metal-binding motif essential for activity. The sequences also divide into groups having either an insert near the $\mathrm{N}$ terminus or an insert near the second catalytic histidine, which may represent extensions of the substratebinding surface. Three of the HiGH61s encode cellulosebinding modules (CBM1). Interestingly, HiGH61H and
\end{abstract}

Electronic supplementary material The online version of this article (doi:10.1007/s00253-012-4206-x) contains supplementary material, which is available to authorized users.

I. Yakovlev · A. M. Hietala $\cdot$ E. Stefańczyk $\cdot$ H. Solheim •

C. G. Fossdal $(\bowtie)$

Norwegian Forest and Landscape Institute,

P.O. Box 115,1431 Ås, Norway

e-mail: foc@skogoglandskap.no

G. Vaaje-Kolstad

Department of Chemistry, Biotechnology and Food Science,

Norwegian University of Life Sciences,

1432 Ås, Norway
HiGH61I having CBM1s are up-regulated on pure cellulose. There was a common substrate-specific induction patterns of the HiGH61s with several reference cellulolytic and hemicellulolytic GHs, this taken together with their low transcript levels on media lacking lignocellulose, reflect the concerted nature of cell wall polymer degradation.

Keywords Heterobasidion spp. · Glycoside hydrolases · GH61 · Wood degradation · Gene expression

\section{Introduction}

The Heterobasidion annosum sensu lato species complex encompasses pathogenic white-rot fungi primarily active in conifer forests that inflict massive economic and ecological losses due to tree mortality and wood decay (Woodward et al. 1998). The Heterobasidion complex comprised three Eurasian (H. annosum sensu stricto, Heterobasidion parviporum, and Heterobasidion abietinum) and two North American (Heterobasidion occidentale and Heterobasidion irregulare) species, each with a different but overlapping host range (Dalman et al. 2010; Niemelä and Korhonen 1998; Otrosina and Garbelotto 2010). Recently, the genome of $H$. irregulare (formerly $H$. annosum North American Ptype) was sequenced and partially annotated (Olson et al. 2012). The annotated gene models reveal a wide repertoire of genes encoding lignocellulose degrading enzymes and these include several members of the family of polysaccharide monoxygenases that are currently classified as family 61 of the glycoside hydrolases (GH61). The GH61s have been predicted to be responsible for the initial step in cellulose breakdown by white-rot fungi, disrupting the cellulosic 
structure allowing subsequent attack by traditional cellulases (Quinlan et al. 2011; Vaaje-Kolstad et al. 2010).

A wide variety of GHs are utilized by wood decay fungi in the degradation of cellulose in plant cell walls. So far, enzymes classified in families GH3, 5, 6, 7, 8, 15, 27, and 48 in the carbohydrate active enzymes database have all been shown to degrade this fibrous and recalcitrant polysaccharide (Cantarel et al. 2009). Until recently, the consensus model for efficient enzymatic decomposition of cellulose was based on the synergistic combination of processive exo-acting cellobiohydrolases and non-processive endoglucanases (Merino and Cherry 2007; Teeri 1997). A disputed, but widely claimed hypothesis for cellulolytic fungi is that also (unspecific) cellulose cleavage by hydroxyl radicals plays an important role in depolymerizing this recalcitrant substrate (Eastwood et al. 2011; Goodell et al. 1997). Such reactions are by some authors suggested to be mediated by Fenton chemistry involving oxidative enzymes such as cellobiose dehydrogenases (CDHs) as electron donors (Mason et al. 2003; Zamocky et al. 2006). However, recent progress in the field has widened the view on the enzymatic factors involved in the deconstruction of cellulose and how these enzymes work in concert. In 2005, a protein (CBP21) of the carbohydrate module 33 family (CBM33) with no apparent enzymatic activity was shown to promote the enzymatic hydrolysis of chitin (Vaaje-Kolstad et al. 2005a; VaajeKolstad et al. 2005b), revealing the existence of nonhydrolytic enhancing factors for recalcitrant polysaccharides as postulated by Reese and co-workers more than 50 years earlier (Reese et al. 1950). The existence of similar enhancing factors for cellulose was actualized upon the finding that fungal proteins classified as family $61 \mathrm{GHs}$ were structurally very similar to CBM33s, sharing a highly conserved metalbinding motif on the substrate-binding surface (Karkehabadi et al. 2008). A verification of the notion that CBM33s and GH61s had a similar function was revealed by a study showing synergy between cellulases and GH61 proteins in the degradation of cellulose (Harris et al. 2010). Harris et al. (2010) was the first to demonstrate a functional role for the GH61 residues forming the metal-binding site by mutagenesis, corroborating the earlier mutagenesis results by VaajeKolstad on CBM33s metal ion-binding histidines (VaajeKolstad et al. 2005b). Recently, a key study on CBM33s acting on chitin showed that these proteins actually are metalloenzymes that cleave the polysaccharide chain through an oxidative mechanism that depends on an external electron donor (Vaaje-Kolstad et al. 2010). Importantly, the latter study also showed that the efficiency of substrate degradation could be greatly improved by providing an external electron donor. The generality of this enzymatic mechanism for cleavage of recalcitrant polysaccharides was recently shown for a CBM33 member (CelS2) that was proven active on cellulose (Forsberg et al. 2011).
Shortly after publication of the studies on CBM33 enzymes, the oxidative reaction mechanism was also shown to apply for GH61 enzymes on cellulose (Phillips et al. 2011; Quinlan et al. 2011; Westereng et al. 2011). GH61s were in addition determined to specifically bind copper, thereby classifying this group of enzymes as copper-dependent monooxygenases (Phillips et al. 2011; Quinlan et al. 2011). Interestingly, it has also been shown that CDHs (naturally secreted in concert with GH61) can act as the external electron donor for GH61 enzymes (Langston et al. 2011; Phillips et al. 2011), indicating a more realistic role for these enzymes than what has formerly been indicated in the field (Fenton chemistry) (Mason et al. 2003; Zamocky et al. 2006). It should be noted that the GH61 proteins were originally classified based on measurement of very weak endo-1,4- $\beta$-D-glucanase activity in one family member (most likely endoglucanase activity). It is now obvious that both CBM33 and GH61 enzymes are erroneously classified and belong to the same group of polysaccharide oxidizing enzymes.

The main aim of the current study is to describe the relationship of GH61 members in H. irregulare and profile their transcriptional regulation and potential co-regulation with other hydrolytic cell wall degrading enzymes upon fungal growth in different natural and defined lignocellulose substrates mimicking the feeding and infectious stages. Transcript level profiles of the GH61s of $H$. irregulare were examined during growth on Picea abies (Norway spruce) heartwood and reaction zone (xylem defense tissue) in order to examine the predominant saprotrophic mode in this host and fungal response to the host defense reaction. Transcript levels during growth on Pinus sylvestris (Scots pine) sapwood were also examined, since sapwood is the tissue colonized by $H$. irregulare in this species. Finally, abundance of GH61 transcripts was analyzed upon H. irregulare growth on pine heartwood, a host tissue heavily impregnated with antifungal compounds that allow only modest fungal growth. As controls, Hagem medium was used to examine for the $H$. irregulare gene expression when feeding on simple sugars and microcrystalline spruce cellulose was used to examine the gene expression on a cellulose substrate devoid of lignin.

\section{Materials and methods}

Samples, strain and culture conditions

The H. irregulare strain TC-32-1 subjected to genome sequencing by the DOE Joint Genome Institute (JGI) was used as the fungal strain in the inoculation experiment (Olson et al. 2012). The TC-32-1 strain is available from the culture collection Norwegian Forest and Landscape Institute, P.O. Box 115, N-1431 Ås, Norway. Liquid Hagem (0.5 g 
$\mathrm{NH}_{4} \mathrm{NO}_{3}, 0.5 \mathrm{~g} \mathrm{KH}_{2} \mathrm{PO}_{4}, 0.5 \mathrm{~g} \mathrm{MgSO}_{4} \times 7 \mathrm{H}_{2} \mathrm{O}, 0.038 \mathrm{~g}$ $(200 \mu \mathrm{M}) \mathrm{MnSO}_{4} \times \mathrm{H}_{2} \mathrm{O}, 0.8 \mathrm{~mL} \mathrm{Fe}(\mathrm{II}) \mathrm{Cl}_{2} \times 4 \mathrm{H}_{2} \mathrm{O}(1 \%$ aqueous solution) and $5 \mathrm{~g}$ malt extract/1 $\left.\mathrm{L} \mathrm{ddH}_{2} \mathrm{O}\right)$ was prepared to be used as a basal medium for all treatments. The $\mathrm{pH}$ was adjusted to 4.5 with $1 \mathrm{M} \mathrm{H}_{2} \mathrm{SO}_{4}$, and after autoclaving, filter-sterilized thiamine $\mathrm{HCl}(0.1 \mathrm{mg} / 1 \mathrm{~L})$ was added. To prepare the inoculum, the fungus was grown on $2 \%$ malt extract agar for 3 weeks at $21{ }^{\circ} \mathrm{C}$ in darkness. Conidiospores were collected from the cultures into liquid Hagem and the spore concentration of the inoculum suspension was adjusted to 300,000 conidia/mL liquid Hagem with the aid of a light microscope and Bürker chamber. To prepare the experimental system, either $2 \mathrm{~g}$ of microcrystalline spruce cellulose powder (Sigma-Aldrich, \#22182), $1 \mathrm{~g}$ of milled (IKA mill 10.2 impact grinding head, IKA Werke, Staufen, Germany) and gamma-sterilized heartwood or reaction zone tissue of Norway spruce ( $P$. abies), or sapwood or heartwood of Scots pine (P. sylvestris) was weighed in a standard 9-cm-diameter Petri dish under aseptic conditions. The wood particles used were about $0.5 \mathrm{~mm}$ in size. For each Petri dish, substrates were wetted with $9 \mathrm{~mL}$ of the inoculum suspension, this small volume allowing aeration of the hygroscopic cellulose and natural lignocellulose (wood) cultures. As a reference treatment, Petri dishes containing only $9 \mathrm{~mL}$ of the inoculum suspension were also prepared. Three replicates were prepared for each substrate and the experiment was harvested after an incubation period of 21 days at $21^{\circ} \mathrm{C}$ in darkness. The samples were stored in $-80{ }^{\circ} \mathrm{C}$ until further processing.

GH61 gene annotation, peptide structure and phylogenetic analyses

Initial search for GH61 family genes was done within the JGI Heterobasidion annosum v2.0 genome web-portal (http://genome.jgi-psf.org/Hetan2/Hetan2.home.html) by means of search facilities using keywords: IPR005103 (InterPro Glycoside hydrolase, family $61 \mathrm{ID})$ and/or PF03443 (HMMPfam:Glyco_hydro_61 ID) as search terms. Selected gene models were confirmed using JGI $H$. annosum NCBI blast server with BLASTP search against the National Center for Biotechnology Information (NCBI) GenBank (http://www.ncbi.nlm.nih.gov/) and the Conserved Domain Database (Marchler-Bauer et al. 2011). Detected putative homologs were characterized based on conserved domains and $E$ values in comparison with known proteins. All gene models containing Glyco hydro 61 pfam03443 or c104076 motif were chosen for further study.

Signal protein sequences were predicted with SignalP 3.0 (http://www.cbs.dtu.dk/services/SignalP; Dyrløv Bendtsen et al. 2004).

All selected GH61 gene models and translated protein sequences were retrieved from the JGI Fungal Genome
Sequence databases. The amino acid sequences were aligned using ClustalW (http://align.genome.jp/) and TCoffee (http://tcoffee.vital-it.ch/cgi-bin/Tcoffee/tcoffee_cgi/ index.cgi) (Notredame et al. 2000), and obtained multiple alignments were adjusted manually with GeneDoc (http:// www.nrbsc.org/gfx/genedoc/index.html). Similarities/identities between selected pairs of DNA or protein sequences were calculated using MatGAT (Matrix Global Alignment Tool) (http://bitincka.com/ledion/matgat/).

Phylogenetic and molecular evolutionary analyses of translated gene sequences (full ORF) of the selected $H$. irregulare GH61 models were conducted using the MEGA5 software (Tamura et al. 2011). The evolutionary history was inferred using the neighbor-joining method. The bootstrap consensus tree inferred from 500 replicates was considered to represent the evolutionary history of the taxa analyzed. Branches corresponding to partitions reproduced in less than $50 \%$ bootstrap replicates werecollapsed. The phylogenetic tree created was linearized assuming equal evolutionary rates in all lineages. The evolutionary distances were computed using the Poisson correction method and are in the units of the number of amino acid substitutions per site as the distance measurement unit. All positions containing alignment gaps and missing data were eliminated only in pairwise sequence comparisons (Pairwise deletion option).

\section{RNA isolation}

Prior to RNA extraction from the inoculation experiment, reaction zone and heartwood samples were aliquoted into 2$\mathrm{ml}$ Eppendorf tubes, and ground twice for $1 \mathrm{~min}$ each time at maximum speed) using a Retsch 300 mill (Retsch $\mathrm{GmbH}$, Haan, Germany) with liquid nitrogen chilled containers and a 100-mg steel bead. Other substrates were ground with a pestle in a liquid nitrogen-chilled mortar. Total RNA was extracted from $100 \mathrm{mg}$ powder of the pulverized wood samples using the MasterPure ${ }^{\mathrm{TM}}$ RNA Purification Kit (Epicentre, Madison, WI, USA, \# MCR85102) following manufacturer recommendation and stored at $-80{ }^{\circ} \mathrm{C}$ until further use. RNA was quantified using a micro-volume spectrophotometer NanoDrop 2000 (Thermo Scientific, Wilmington, DE, USA).

\section{cDNA synthesis and qRT-PCR}

Transcript levels of selected genes were determined for mycelium growing on six different media (Hagem, cellulose, spruce heartwood and reaction zone, and pine heartwood and sapwood) described above, using quantitative RTPCR. Gene specific primers were designed using Primer3 (Rozen and Skaletsky 2000) and following criteria: melting temperature $70{ }^{\circ} \mathrm{C}$ and product size inferior to $120 \mathrm{bp}$. The list of studied gene homologs and their primer sequences are 
shown in Table S4 in the Electronic supplementary material (ESM). Total RNA was reverse transcribed (300 ng/reaction) using the TaqMan Reverse Transcription kit (Applied Biosystems, Carlsbad, CA, USA, \# 8080234) in 50- $\mu 1-$ reaction volume. PCR amplification was performed in a $25-$ $\mu \mathrm{l}$-reaction volume, using $2 \mu \mathrm{l}$ of fourfold diluted cDNA solution as template, $12.5 \mu \mathrm{l}$ of $\times 1$ SYBR Green master mix and $200 \mathrm{nM}$ of each primer. RT-PCRs were performed using the 7500 Fast Real-time PCR System (Applied Biosystems, Carlsbad CA, USA) with standard cycling parameters. All reactions were done in triplicate and no-template control was run for each primer pair. For data analysis, the arithmetic mean of two biological replicates was calculated. Target gene expression was normalized to geometric mean of genes encod-

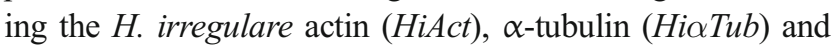
ubiquitin-conjugating enzyme $2(\mathrm{HiUbc2})$ (Table $\mathrm{S} 4$ and Fig. $\mathrm{S} 1$ in the ESM).

Absolute quantification was performed using 7500-system SDS software. The qRT-PCR Data were further processed in MS Excel and analyzed using the $\mathrm{RT}^{2}$ Profiler PCR Array Data Analysis Version 3.5 web portal from SABiosiences/Qiagen (Frederick, MD, USA) (http://pcrdataanalysis.sabiosciences. com/pcr/arrayanalysis.php) using portal defaults, to obtain pvalues and correlation coefficients for each gene product (Tables S7 and S8 in the ESM).

\section{GH61 gene amplification and sequencing}

In order to confirm the predicted $G H 61$ gene models, the coding regions of the GH61s in H. irregulare and H. parviporum (a species primarily associated to Norway spruce) were PCR amplified and sequenced.

For $H$. irregulare RNA was obtained from colonized cellulose medium while for $H$. parviporum we used RNA from natural infection of Norway spruce (Yakovlev et al. 2008). Full-length doubled-stranded cDNAs were obtained from $1 \mu \mathrm{g}$ of RNA using the SMART-PCR cDNA Synthesis Kit (Clontech, Palo Alto, CA, USA). PCR amplification of the full-length coding cDNA, from the start to the stop codons, was performed on a GeneAmp 9600 thermocycler (Perkin-Elmer Instruments, Shelton, CT, USA) using the Advantage 2 Polymerase Mix (Clontech). Primers were designed using the nucleotide sequences of selected $H$. irregulare GH61 gene models (Table S5 in the ESM) and used for both species. The PCR products were analyzed in parallel on a $2.0 \%$ agarose gel stained with ethidium bromide. Amplified products (single and multiple clear bands) were excised from gel, purified with the Qiagen MinElute Gel Extraction Kit (Qiagen, \#28606), and sequenced directly from both sides using the corresponding cloning primers. The obtained sequences were assembled into contigs using the SecMan Pro module of DNAStar Lasergene sequence analysis software suite (DNASTAR Inc., Madison, WI).
Contigs for each of the Heterobasidion species were aligned with $H$. irregulare gene model sequences and between species. Sequences of the $H$. parviporum cDNAs described in this study are available at the NCBI database under accession numbers JQ290102 to JQ290109.

\section{Molecular modelling}

A sequence alignment representing the starting point of the modeling procedure was prepared by extracting the HiGH61A and TtGH61E (PDB ID: 3EII) (Harris et al. 2010) sequences from a ClustalW generated structure based multiple sequence alignment (MSA) generated for all HiGH61 sequences (see above) and converted to PIR format with "gap-only" columns removed. The alignment was used to build the 3D molecular model of HiGH61A, running MODELLER 9v4 (Eswar et al. 2007) and using the TtGH61E crystal-structure as structural template. The 3D models of HiGH61A were selected from 20 models, based on the value of the Modeller objective function, and further refined. The energy configuration outputs of the best-ranked models were used as starting parameters for loop optimization, followed by energy minimization using a constrained $\mathrm{C} \alpha$ backbone. The stereochemical quality and overall Gfactor of the optimized model was calculated with Procheck (Laskowski et al. 1993) and the compatibilities of the models with overall folds were estimated with ProSA-web (Wiederstein and Sippl 2007). The root-mean-square deviation (RMSD) values in the $\mathrm{C} \alpha$ backbone positions between the HiGH61A model and 3EII was determined using the 'super' algorithm in PyMol (http://www.pymol.org) that was also used for generation of molecular graphics (DeLano 2002). Analysis of the accessible molecular surface was done using the WHATIF software (Vriend 1990).

\section{Results}

Sequence analysis and structural modeling of HiGH61 sequences of $H$. irregulare

In total, ten genes coding for candidate proteins of the glycoside hydrolase family 61 (GH61) were identified (Table S1 in the ESM). The HiGH61 family genes are relatively dispersed throughout the $H$. irregulare genome and placed at scaffolds 01, 03, 05 (two genes), 07, 08, 09, 10 (two genes), and 13. The two genes, $H i G H 61 G$ and $H i G H 61 I$, are adjacent to each other at scaffold 5 within $<4 \mathrm{~kb}$ genomic interval with $46 \%$ of identity (Table $\mathrm{S} 2$ in the ESM).

All the analyzed HiGH61 polypeptide sequences contain a 16-22 aa long secretory signal peptide at the $\mathrm{N}$ terminus. The deduced amino acids sequences of full-length HiGH61 genes varied in length from 233 to 343 amino acids and the 
respective genomic sequences contained multiple exons (from 4 to 11) (Table S1 in the ESM). All mature HiGH61 polypeptide sequences share the conserved metal ionbinding site that contain two histidines included in the $\mathrm{N}$ terminus of the mature protein, except HiGH61G where these histidines have been replaced by arginine and glutamine, respectively (Fig. 1).

In addition to the conserved metal-binding motif, four proteins (HiGH61D, HiGH61H, HiGH61I, and HiGH61J) also possess an additional single domain at the C-terminal side of the GH6 module. For HiGH61D, HiGH61H, and HiGH61I, the extra domain was identified as a family 1 carbohydrate-binding module (CBM1; also known as fungal cellulose-binding domain) (Gilkes et al. 1991), whereas HiGH61J has a C-terminal extension of $\sim 35$ residues of unknown function.

A MSA of the $H$. irregulare GH61 sequences was obtained by aligning the sequences to a profile consisting
TtGH61E HjGH61B HiGH61A HiGH61B HiGH61J HiGH61C HiGH61D HiGH61F HiGH61H HiGH61G HiGH61I HiGH61E
TtGH61E HjGH61B HiGH61A HiGH $61 \mathrm{~B}$ HiGH $61 \mathrm{~J}$ HiGH61C HiGH61D HiGH61F HiGH $61 \mathrm{H}$ HiGH61G HiGH61I HiGH61E

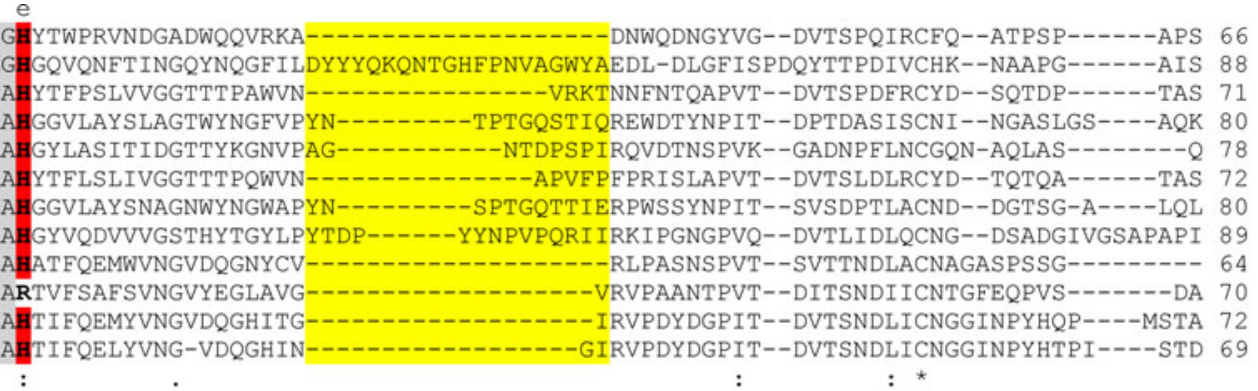

VLNTTAGSTVTYWANP ATAAA-GSNIVFQWGP TITVAAGAQLGIMSDG -SATVAAGSSVTAYWN-TITVVAGTQLGVACDT TATVAAGSAITAYWN--YGTVAAGQQVNLNWTT VITVPAGATVTASFHKTSAGYLGPDPADPIDP- IITVPAGAQVTTEWHHTLAGADPSDSADPIDP--SH VANANPGSKIDFLWSDIG-. LCAVNPGDSVTVEMHOQP----GDRSCATEATGGD IITVPAGATLTAEWHHTLDGADPSDPADPIDP--SH

e GVWP PYGPIVTYVVECS--GSCTTVNKNNLRWVKIQEAGINYN--TQV-WAQQDLI-NQGNKWTVKIP 166 TIYHP-GVVNVYMAKAPD-GDAATFDGSGTVWFKVYQISAVTDGGTSISWPAONL-----AGVTFTLP 148 OWP HTIGPVMVYMANCG--GDCTTATTSSLEWFKINQVGLVSGTLTSGTWGMGOLV-ANNNSWTTSIP 160 SNWPHNTGPVMTYMAKCDG--TCDKYNSTDAQWFKVDELGMKPD---GSTWYQQDIM--NGQPVSVTLS 158 TIYHP-GVVNVYMAKAPD-GDVSTEDGSGTVWFKVYQISAVTNGGTSISWPAQDL-----SSVIFTLP 149 AYGPMLTYLAQCPG-TTCTGVDATTLKWFKIDEAGLLSGTVYDGYWGDGOMI-AONSSWTTTIP 162 V-GPMITYMAKAPS-DITQWLPGTSAVWFKVAEAGKTSD----GKWASTDILSADQSIYTFTVP 169 -GPINIYLAKVS---DATTAVGSSASWFKISEMGLPSS--DPDYWATEVLN-DNCGHFTFTIP 153 KGPLTAYLAVVP---DATOANVTGLKWFKIWEDGLSGQ----ROWGSDRLF-INGGNATFTIP 159 K-GPI I AYLAKVP---SATQSTVTGLQWFKIYEDGMESD----QSWGVDRLI-ANKGKVSFTIP 161 -GPVISYLAKVN---NATQTDVTGLQWFKIYEDGYTPS---DAQWAVDRLI-ANKGRVTFTVP 159 ${ }^{\star} .{ }^{\star}:$ : $\therefore$

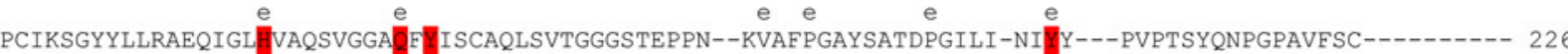
SSLRPGNYVFRHELLAA KNLPTGQYLVRMEAIAL SSLAAGNYILRHELLAI NDIAPGQYLIRHEIIAL SALPTGQYLVRLEAIAI KTVPSGNYLIRFETIAI ANLQAGQYIVRHEIIAL TGIAPGQYLLRAEVIAL SCIODGOYLLRVEDIALQS SCIEAGQYLLRAEIIALF

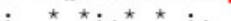

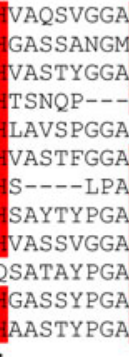

PQCVNIAVTGSGTKALPA--GTPATQLYKPTDPGILF-NP SCGQINVTGGGSGSPGP--VVAIPGVYTGYEPGILININ S--HETETNYTI PGPAVWQG-------- 244 PSCTQVNIGGSQTGQPNQ--TVTFPGGYTDTEPGILVPDVEN----PGLVYSFPGPAMSNLAAIADTATGQ 252 LSCGQINVTGGGSGAPGP--LVAIPGVYTGYEPGILINIDY----PIPANYTQPGPLVWSG---------- 233 PECAQILITGGGTLQPTAAELVTFPGGYGANDPGLVI -DI YSNTAQSOTTYPIPGPPLYGSSGSSSGSAPP 257 MSCFQLNVGGSGTAQPSA---VNIPGAYGASDPGILI-NI YQ----SLTAYTIPGPTPYGTTSPTVATTAW 245 FMSAOIEVTGGGSAVPAT---VSFPGAYTSTDPGIVA-NI YT-----LQSYTPPGPAVFTC---- - - - - 240 FECAQLQITGGGSTSPAT---VSFPGAYSGTDPGIKI-NI Ye----TLPSYTVPGPAVFSCNGSTAPAP-- 251 MECAQLQITGGGSTQPAT---VSFPGAYKSSDPGITI-NIYE----TLSSYTIPGMFDLHMILPTPCS--- 248 $\star \quad::$ : . PSCIQLQVTGSGTKLPTS--FVSFPGAYTPTTPGIVY-DVYT----NTSAYPIPGPAVWTGN--------- 252
TtGH61E

HjGH61B

HiGH $61 \mathrm{~A}$

HiGH61B

HiGH61J

HiGH61C

HiGH61D

HiGH61F

HiGH61H

HiGH61G

HiGH61I

HiGH $61 \mathrm{E}$

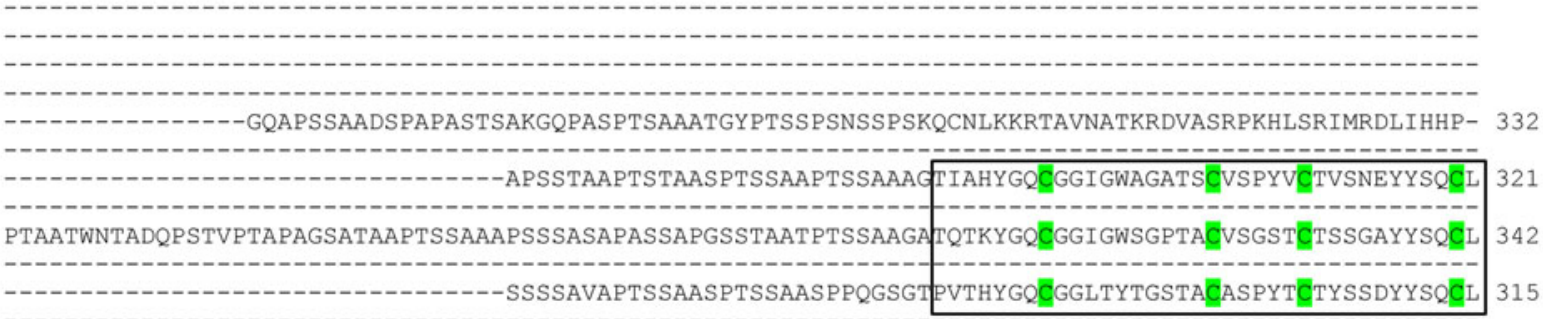

SSSSAVAPTSSAASPTSSAASPPQGSG

Fig. 1 Multiple sequence alignment of HiGH61 sequences and sequences of GH61 proteins with known 3D structures (TtGH61E from $T$. terrestris and HjGH61B from $H$. jecorina). Regions with insertions/deletions are shaded yellow (region 1) and blue (region 2). Conserved residues clustered on the putative substrate-binding surface/ active site are shaded red. Degree of conservation: asterisks fully conserved, colons highly conserved, and full stops moderately conserved. Conserved residues with solvent exposed side chains (inferred by analysis of the HiGH61A 3D model by WHATIF) are marked with an "e". CBM1 domains are indicated by a box and the conserved cysteines within these modules are colored green 
of a 3D-structural alignment of TtGH61E and HiGH61B from Thielavia terrestris; PDB ID: 3EII (Harris et al. 2010) and Hypocrea jecorina; PDB ID: 2VTC (Karkehabadi et al. 2008), respectively (Figs. 1 and 2). In order to aid and visualize the interpretation of the MSA, a 3D model of HiGH61A was made using the MODELLER software using the TtGH61E structure as template $(41 \%$ sequence identity and $3 \%$ gaps). Analysis of the HiGH61A 3D model reveals that the majority of conserved residues of the HiGH61

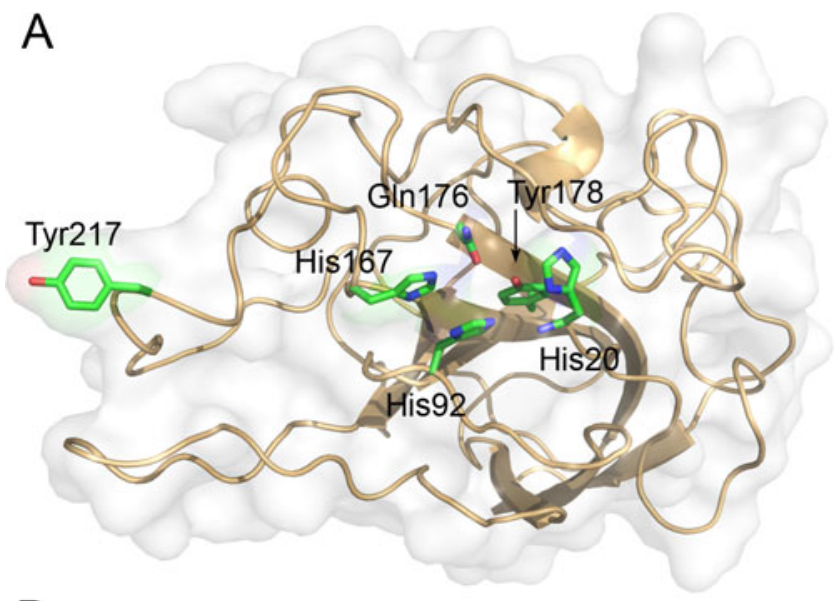

B

Putative substrate binding surface

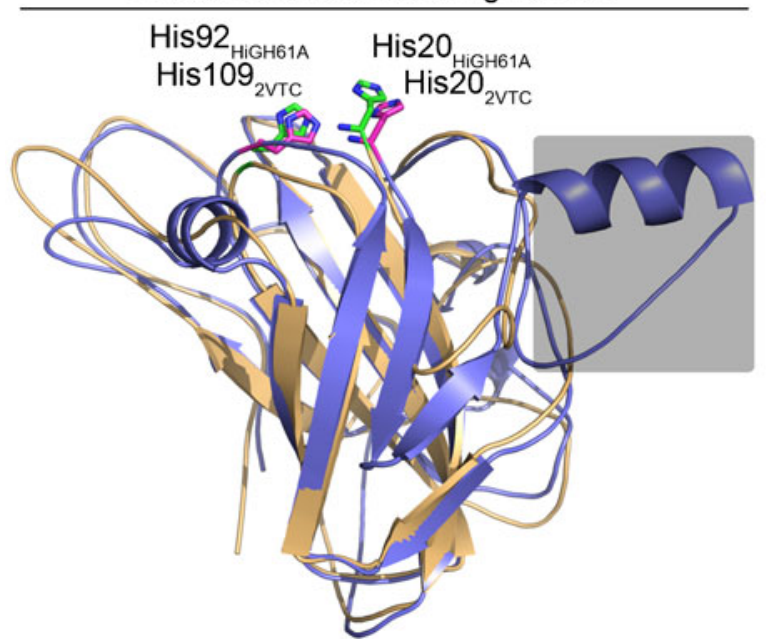

Fig. 2 3D structural model of HiGH61A. a A superposition of the HiGH61A model (light-orange cartoon) and HjGH61B (PDB ID: 2VTC; blue cartoon) illustrating the binding surface extension seen in some of the HiGH61 proteins (sequence part covered by a grey shaded box; see also Fig. S1 in the ESM). The putative substratebinding surface is seen from the side and also indicated by a line. The two conserved metal-binding histidines that are essential for GH61 activity (metal not shown) are shown in stick representation (colored green for HiGH61A and magenta for HjGH61B). b H. irregulare, a view looking down on the putative HiGH61A substrate-binding surface (i.e., rotated $90^{\circ}$ around the $x$-axis compared with (a)) with the conserved, solvent-exposed amino acids shown in green stick representation. The protein is visualized in light-orange cartoon representation surrounded by a transparent white molecular surface isozymes are found internally in the protein where they most likely contribute to stabilizing the protein fold, similar to what is observed in a study on GH61s from T. terrestris (Harris et al. 2010). Analysis of the accessible molecular surface shows that only 11 of the 52 conserved residues have solvent exposed side chains, whereof six are present on the putative substrate-binding surface (Fig. 2). These include His20 and His92 that are involved in the metalbinding motif and additionally Gln176, His 167 , Ile215, and Tyr217 that are likely to play important roles in the catalytic mechanism/substrate binding of these proteins. Tyr217 is the only aromatic amino acid in the protein that is solvent exposed, much like what is seen for the chitin oxidizing enzyme CBP21 (Vaaje-Kolstad et al. 2005b), where it has been shown to be important for activity and substrate binding (Vaaje-Kolstad et al. 2005a).

Evaluations of stereochemical parameters of the final model showed no residues in the disallowed region of the Ramachandran plot (analyzed by Procheck), (Laskowski et al. 1993), overall $\mathrm{G}$-factor obtained $=-0.2$, an $\mathrm{RMSD}$ value of the $\mathrm{C} \alpha$ positions between the HiGH61A model and TtGH61E of $0.18 \AA$ (analyzed using the "super" algorithm in Pymol (DeLano 2002) and an overall good model quality ( $Z$ score $=-5.12$ ) when analyzed by the ProSA software designed for detection errors in protein structures (Wiederstein and Sippl 2007).

\section{GH61 phylogeny}

The phylogenetic tree was inferred from the alignment of most of the GH61 proteins found in the JGI genomic database using the neighbor-joining method (Fig. 3). In addition to the 10 GH61 protein sequences from $H$. irregulare, proteins from the saprotrophic white-rot fungi Phanerochaete chrysosporium (14), Pleurotus ostreatus (29), and Schizophyllum commune (14); the saprotrophic brown-rot fungi Postia placenta (4) and Serpula lacrymans (5); the mycorrhizal fungus Laccaria bicolor (14); and the leaf litter decayer Agaricus bisporus (11) were also included (Table $\mathrm{S} 3$ in the ESM). H. irregulare GH61 proteins clustered into five different diverse groups without obvious species or decay mode specificity. Two protein pairs stood out with very-high-sequence similarity; HiGH61E and HiGH61F with $61 \%$ of identity and HiGH61A and HiGH61C having $\approx 00 \%$ of identity (Table S2 in the ESM). HiGH61A and HiGH61C grouped in the same branch as TtGH61E from $T$. terrestris.

Comparison of GH61 family coding sequences between $H$. irregulare and $H$. parviporum

Amplification of GH61 genes in H. irregulare samples produced in all cases single PCR products with expected 


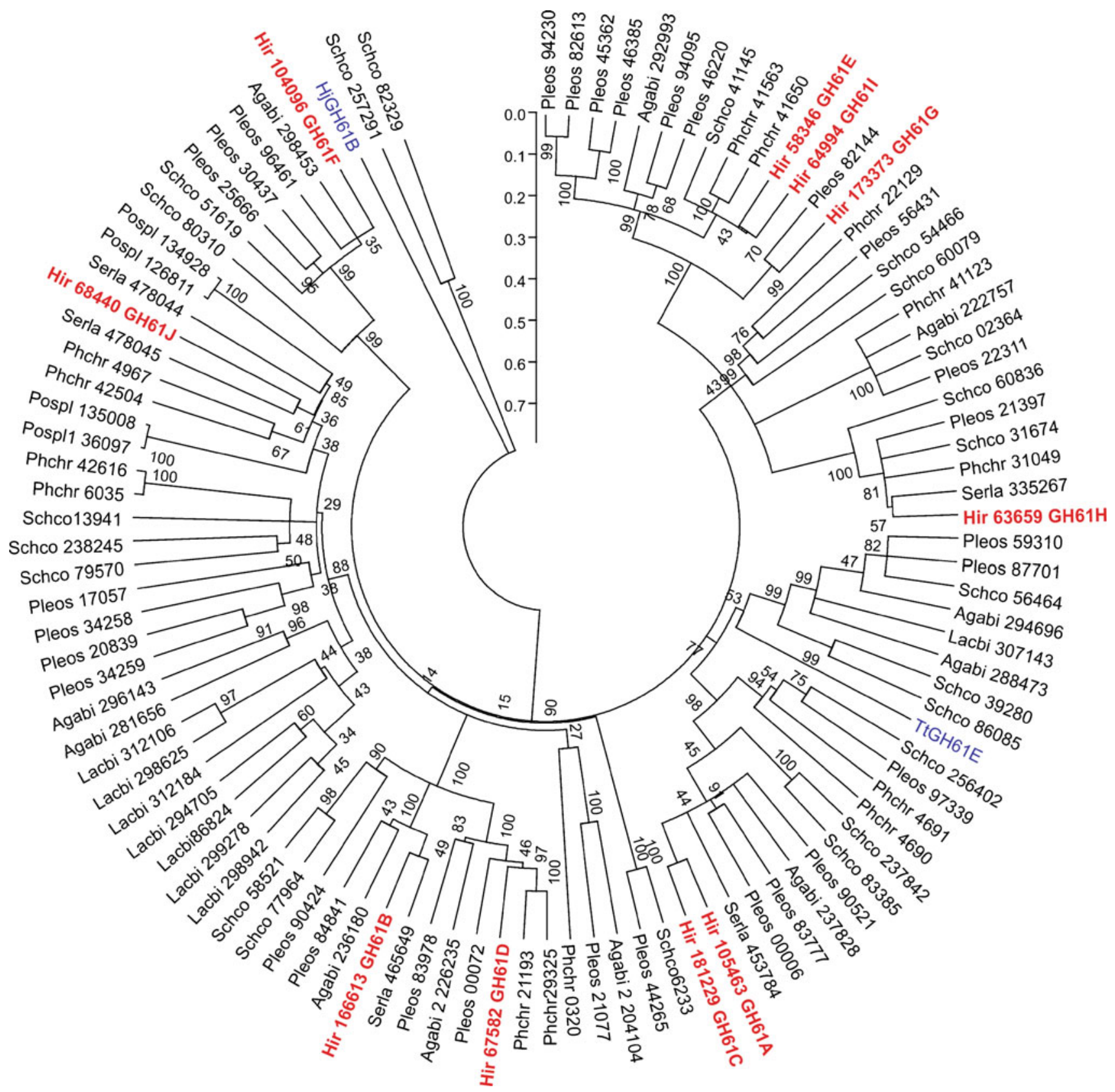

Fig. 3 Phylogenetic tree of GH61 family proteins (full ORF amino acid sequences) available at the JGI fungal genomic database. Species abbreviation and protein ID are shown for each entry. The phylogenetic tree was constructed using MEGA5 as detailed in "Materials and methods." The tree is drawn to scale, with branch lengths in the same units as those of the evolutionary distances used to infer the phylogenetic tree. Sequences from $H$. irregulare (Hir) are shown in red. Fungal species: Agabi A. bisporus, Pleos P. ostreatus, Pospl P. placenta, Lacbi L. bicolor, Phchr P. chrysosporium, Serla S. lacrymans, Schco S. commune, TtGH61E from $T$. terrestris and HjGH61B from H. jecorina product size, except for $H i G H 61 C$ and $H i G H 61 E$, which showed faint PCR products. Amplification of GH61 genes in $H$. parviporum samples produced clear single PCR products with expected product size only for $H p G H 61 G_{-}^{-}$ $H p G H 61 J$, multiple bands for $H p G H 61 A-H p G H 61 F$ and no amplification product for $H p G H 61 C$ and $H p G H 61 E$ (Table S6 in the ESM). The obtained multiple bands for $H$. parviporum, when bright and clear on gel, were also sequenced. In all cases the sequences obtained from $H$. irregulare corresponded to predicted gene model sequences. The $G H 61 G-G H 61 J$ gene sequences revealed clear single nucleotide polymorphisms between the two species, some being non-synonymous. The HpGH61J sequence showed a synonymous insert of $21 \mathrm{bp}$ (7 aa). Most of sequenced 
fragments excised from $H$. parviporum samples with multiple PCR products were not related to GH61 family genes or were not found in the $H$. irregulare genome.

Transcription patterns of $H$. irregulare GH61 family genes

Gene expression data of ten HiGH61 family genes and twelve reference genes with carbohydrate active gene products were profiled on four natural substrates (liquid Hagem supplemented with heartwood and reaction zone of Norway spruce, sapwood and heartwood of Scots pine) and two defined substrates (cellulose supplemented liquid Hagem and sole liquid Hagem) using qRT-PCR (Figs. 4 and 5, respectively). The basal liquid Hagem medium was considered as control and all normalized gene expression data were related to transcript level on Hagem medium. All the GH61 family genes were expressed but showed differential expression between the different substrates. Most of the GH61

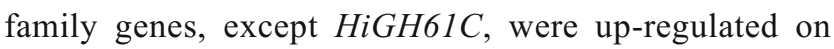
spruce heartwood (up to $\approx 17,000$-fold change (FC)) and reaction zone (up to $\approx 8000 \mathrm{FC}$ ), the genes $H i G H 61 \mathrm{~A}$, $H i G H 61 B$, and HiGH61G-HiGH61I being highly induced on both substrates (above 200 FC). Similarly, most of the GH61 family genes, excluding $H i G H 61 E$, were upregulated on pine sapwood, the genes $H i G H 61 G-H i G H 61 I$ showing the highest transcript levels ( $\geq 300-4,000$ FC). On pine heartwood only $\mathrm{HiGH61H}$ showed the highest transcript levels (up to $\approx 80 \mathrm{FC}$ ) while the remaining $G H 61$ genes were either slightly induced or down-regulated (HiGH61C, HiGH61D, and HiGH61E). On cellulose, most of the $G H 61$ family genes, excluding $H i G H 61 H$, tended to increase.

In general, the highest transcript levels of GH61 family genes were observed on spruce heartwood, followed by spruce reaction zone, pine sapwood, cellulose and pine heartwood. Among the profiled GH61 genes HiGH61H clearly showed the highest induction, whereas HiGH5.1 (a GH5 cellulase encoding gene) together with the HiGH7 (GH7 cellulase) and $\mathrm{HiCDH1}$ (encoding a cellobiose dehydrogenase) showed the highest induction among the carbohydrate active reference genes.

HiGH61A, HiGH61B, and HiGH61D-HiGH61I; HiGH5.1 and HiGH5.2; HiGH7; and HiCDH1 appeared to be coordinately regulated on all substrates (Figs. 4 and 5; Table S7 in the ESM). HiGH61C showed similar tendencies in substrate-specific transcript level patterns with $\mathrm{HiGH} 27$ and HiLcc2, whereas HiGH61J showed correlation in transcript level patterns with HiGH15, HiGH88.1, and $\mathrm{HiCDH} 2$.

Transcription patterns of $H$. irregulare $\mathrm{CDH}$ family genes

Two cellobiose dehydrogenase genes have been described in $H$. irregulare genome. The proteins encoded by these genes

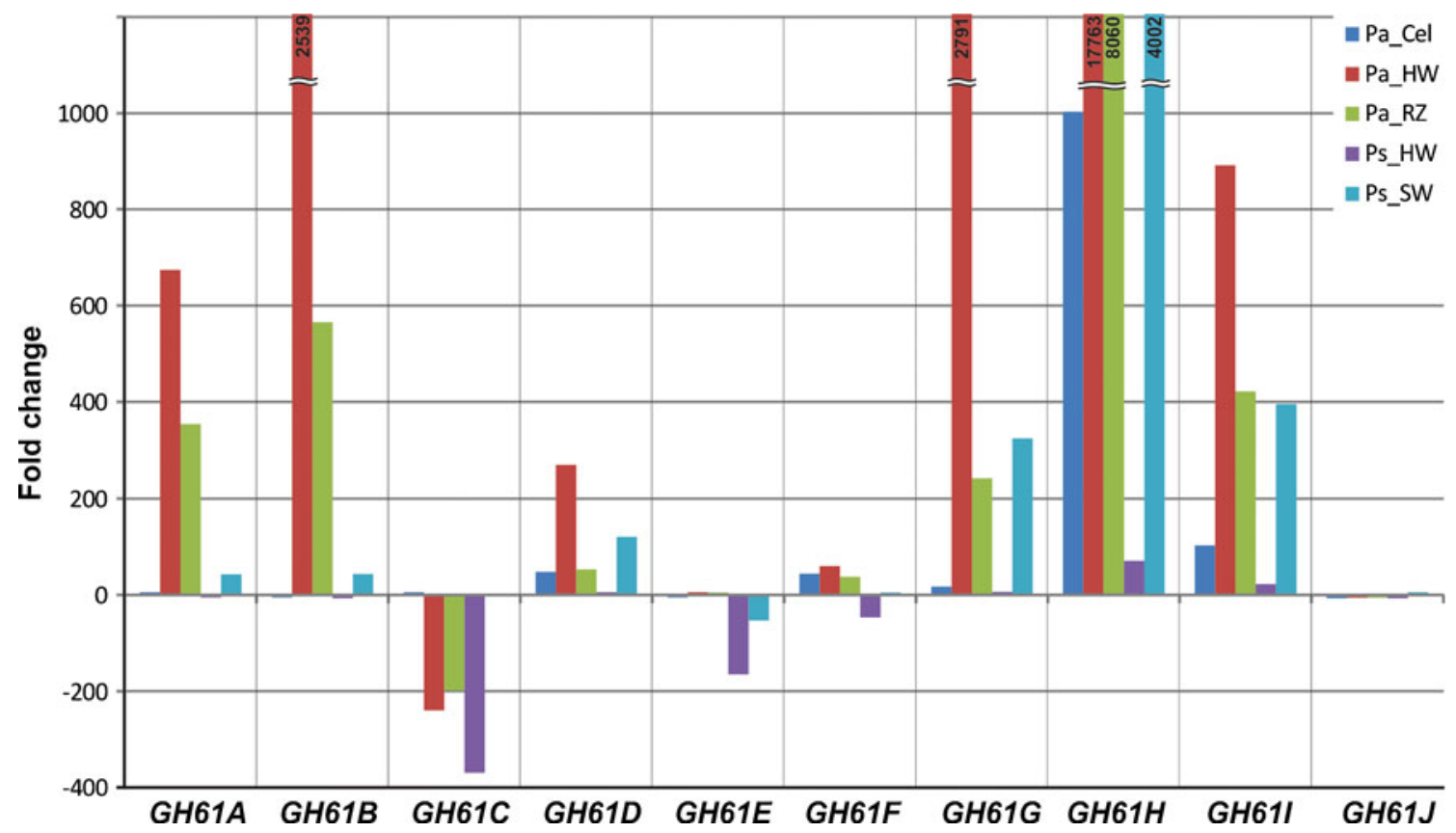

Fig. 4 Transcript level profiles of GH61 polysaccharide oxidases of $H$. irregulare during fungal growth on different substrates from $P$. abies $(P a)$ and $P$. sylvestris (Ps). Substrates: Cel cellulose, $R Z$ powdered reaction zone wood of Norway spruce, $H W$ powdered heartwood wood of Norway spruce and Scots pine, $S W$ powdered sapwood of Scots pine. Analysis was based on three biological replicates per culture medium. Transcript levels, normalized to the geometric mean of HiAct, $H i \alpha T u b$, and HiUBC2 Ct values (endogenous controls), are shown as fold changes in relation to their normalized transcript levels on the control medium (liquid Hagem) 


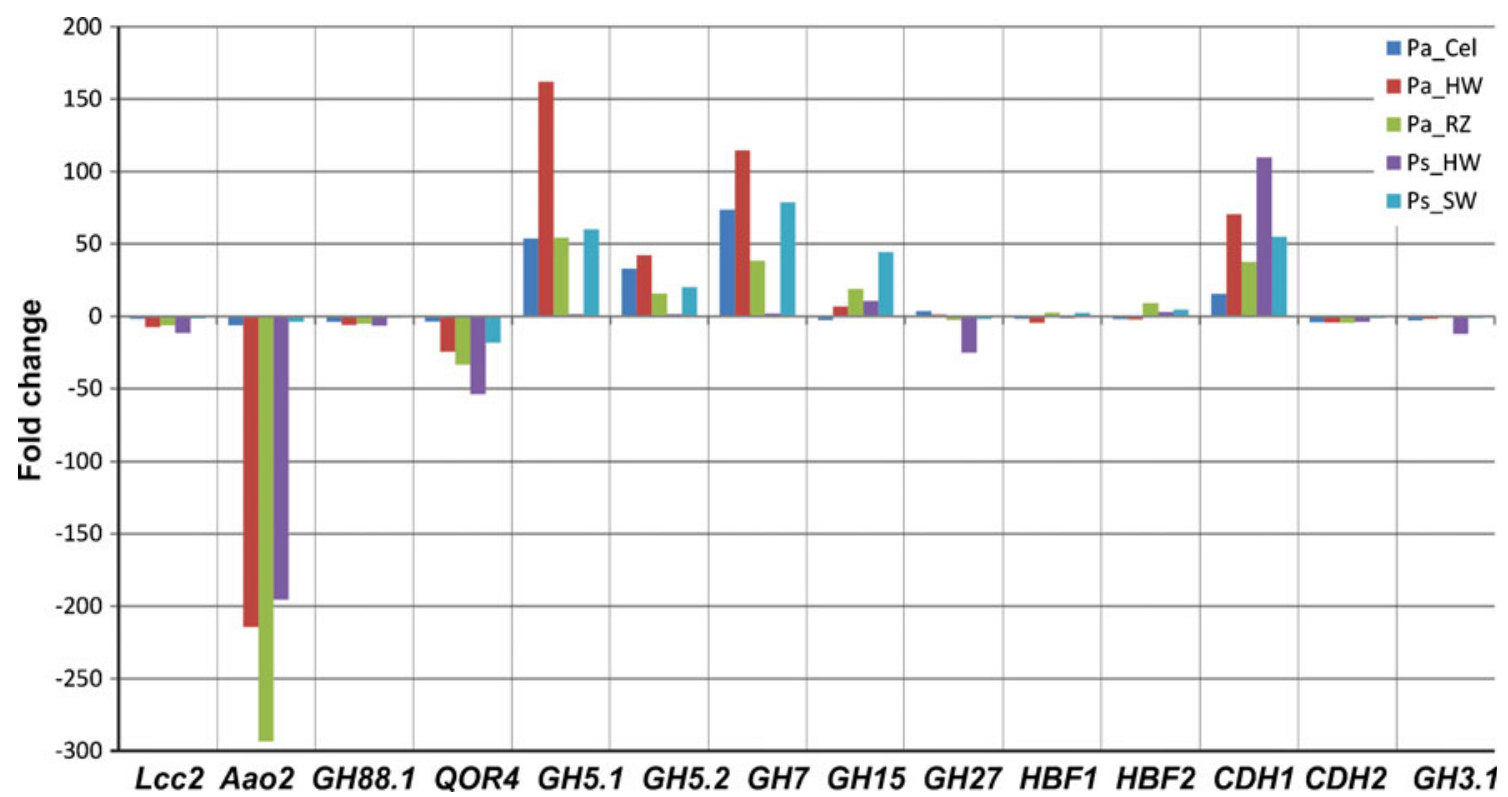

Fig. 5 Transcript level profiles of selected lignocellulose active genes of H. irregulare (see legend of Fig. 4 for more information). Lcc laccase 2, Aao aryl-alcohol oxidase, $Q O r$ quinone oxidoreductase, $C D H$ cellobiose dehydrogenase, $H B F$ hydrophobin, $G H$ glycoside hydrolase

are secreted and contain the common cellobiose dehydrogenase/carbohydrate-binding 9 domain (IPR015922) but differ significantly by sequence and structure. $\mathrm{HiCDH} 1$ encodes a large protein of 775 aa containing N-terminal cellobiose dehydrogenase domain followed by a glucose-methanolcholine oxidoreductase domain (IPR007867) or FAD/NAD (P)-binding domain (SSF51905). HiCDH2 encodes a smaller protein of 285 aa containing $\mathrm{N}$-terminal cellobiose dehydrogenase domain followed by a carbohydrate-binding module 1 (CBM1) (PF00734).

Transcription patterns of the two $C D H$ genes were different: while $\mathrm{HiCDH1}$ was upregulated on all substrates, $\mathrm{HiCDH} 2$ was only slightly expressed and downregulated on all substrates. The maximum transcript levels for $\mathrm{HiCDH1}$ were observed on pine heartwood of spruce, followed by spruce heartwood, pine sapwood, and spruce reaction zone (Fig. 5). HiCDH1 transcript levels correlated with transcript levels of most of GH61 genes, except $\mathrm{HiGH61F}$ and $\mathrm{HiGH61J}$. For HiCDH2-positive correlations in substrate-dependent transcript level, patterns were found with HiGH61J and two GH genes (HiGH88.1 and HiGH15), but for all of these, the expression appears to be constitutive and largely unaffected by the treatments (Table S7 in the ESM).

\section{Discussion}

The recent evidence for GH61/CBM33 proteins being oxidative polysaccharide cleaving enzymes (Forsberg et al.
2011; Phillips et al. 2011; Quinlan et al. 2011; VaajeKolstad et al. 2010; Westereng et al. 2011) has established a new line of thought on how microbes depolymerize recalcitrant biomass. In this respect, $H$. irregulare is a typical representative of cellulolytic fungi as it possesses ten genes encoding GH61 enzymes (fungi with over 40 GH61 encoding genes have been reported, e.g., Chaetomium globosum (Longoni et al. 2012)). Sequence analysis of these genes reveals that all except HiGH61G possess the conserved metal-binding motif that is essential for activity (Fig. 1). The sequences also divide into groups having either an insert near the $\mathrm{N}$ - terminus (Fig. 1, yellow shading) or an insert near the second catalytic histidine (Fig. 1, blue shading), which both may represent extensions of the substratebinding surface. Three of the enzymes also contain Cterminal cellulose-binding modules (CBM1), indicating direct targeting of crystalline cellulose.

The transcription data of the HiGH61 genes divides this enzyme class into two different groups; one showing clear up regulation on some or all substrates (HiGH61A, $H i G H 61 B, H i G H 61 D, H i G H 61 G, H i G H 61 H$, and HiGH61I) and the other showing either down-regulation or unaltered gene expression compared with the control medium (HiGH61C, HiGH61E, HiGH61F, and HiGH61J). This grouping suggests that the fungus up- or down-regulate different sets of GH61s depending on the substrate used for growth, like in the various stages of necrotizing and saprotrophic growth on the host. Interestingly, all GH61s that have a CBD domain at the C-terminal (GH61D, $G H 61 H$, and GH61I) are up-regulated on all substrates 
except heartwood of Scots pine and are the only GH61s that show clear up regulation in the pure cellulose substrate (Fig. 4), indicating that at least these three GH61s are designed to specifically target cellulose surfaces. The most highly induced HiGH61 (HiGH61A, HiGH61B, HiGH61D and HiGH61G-HiGH61I) genes showed the highest observed transcript levels on spruce natural substrates, higher on spruce hearth wood than in spruce reaction zone wood possibly reflecting is pivotal role in the decomposition of cellulose during this preferred saproptrophic mode in this host. HiGH61A, HiGH61B, HiGH61D, and HiGH61GHiGH61I are induced on pine sapwood, while close to constitutive levels is detected on pine heartwood (resinous wood with antifungal properties), possibly reflecting that colonization of the pine sapwood is the predominant growth mode in this host. The additional two GH61 genes (HIGH61C and HIGH61J) appeared to be coordinately expressed with HiLcc2 (encoding a laccase), leading us to speculate that these GH61s may play a role beyond cleaving cellulose. The common upregulated transcription patterns of most GH61 genes together with several of the reference cellulolytic and hemicellulolytic GHs (GH5 and GH7 cellulases) during growth on the natural woody substrates reflect the co-metabolic nature of cell wall polymer degradation.

Sequence and phylogenetic analysis of the $H$. irregulare GH61s shows high sequence divergence (Figs. 1 and 3). Similar divergence has been shown for other ascomycetes and basidiomycetes fungi (Harris et al. 2010), indicating that much of the duplication and divergence of the genes encoding GH61 proteins is a fairly ancient evolutionary event. This diversity has been largely maintained and in some cases apparently amplified during this evolutionary span, suggesting a significant selective pressure to retain a heterogeneous collection of GH61-encoding genes in cellulosedegrading fungi (Harris et al. 2010). The high level of indel and single-nucleotide polymorphism observed when comparing $G H 61$ s between the closely related $H$. irregulare and H. parviporum species (Table S6 in the ESM) is compatible with this hypothesis. Generally white-rot fungi have more of GH61 family proteins than brown-rot fungi, and this also applies for $H$. irregulare which possessed ten members in the gene family, whereas the reference brown rot fungi $P$. placenta and $S$. lacrymans have four and five members, respectively (Table S3 in the ESM). Among white-rot fungi, the necrotrophic and saprotrophic $H$. irregulare possesses the lower number of GH61 family genes (10) in comparison with saprotrophic P. chrysosporium (14), P. ostreatus (29), and S. commune (22). Notably, fungi growing on hardwoods (non-monocot angiosperm trees) generally possess more GH61 family genes than fungal species growing mostly on softwoods (wood from conifers that are gymnosperms), like $H$. irregulare and P. carnosa (this could be due to the more complex cell wall chemistry and that the lignin composition and their links to cellulose is more complex in angiosperm trees).

Detailed analysis of the $H$. irregulare GH61 polypeptides enabled identification of a region in the GH61 sequences that may contain insertions/deletions (Figs. 1 (yellow-colored part of MSA) and 2a). This region provides an extension of the protein surface next to the metal-binding site (Fig. 2; also observed for HjGH61B), putatively providing means of substrate binding as this region also contains exposed aromatic amino acids that are known to interact with carbohydrates. A second insertion is observed in the HiGH61H, HiGH61G, HiGH61I, and HiGH61E sequences close to the second conserved His in the metal-binding motif (Fig. 1 (blue-colored part of MSA)), which may also expand the putative substrate-binding surface residues important for GH61 activity clustered at the putative reactive surface of the GH61s (Fig. 2b; His20, His92, His167, Gln176, Tyr178, and Tyr217-HiGH61A numbering) are conserved in all proteins except HiGH61G and HiGH61J (Fig. 2). Interestingly, HiGH61G has most of these residues substituted with amino acids that are likely to be incompatible with the cellulose oxidizing activity proposed for proteins in the GH61 family (His $20 \rightarrow$ Arg, His $92 \rightarrow$ Glu, His $167 \rightarrow$ Gln, and Tyr178 $\rightarrow$ Phe, HiGH61A numbering; Figs. 1 and 2b; (Vaaje-Kolstad et al. 2010) while HiGH61J shows two substitutions of these conserved residues; Gln176 $\rightarrow$ Glu and Tyr217 $\rightarrow$ Phe.

It is intriguing to note that $H i G H 61 G$ is highly upregulated on several substrates (Fig. 4) since this protein lacks amino acids essential for the predicted GH61 oxidative activity (the sequence of this gene was verified by sequencing of PCR products from two species, independent isolates). It may be that this protein has evolved a different enzymatic function or even a non-enzymatic role compared with other GH61 enzymes. The putative enzymatic properties of $H i \mathrm{GH} 61 \mathrm{G}$ should be further characterized in order to reveal the functional significance of this protein.

Recent work (Langston et al. 2011) demonstrated that cellobiose dehydrogenase can provide electrons to GH61s to form an oxidoreductive system for microbial lignocellulose degradation. The two $C D H$ genes of $H$. irregulare differ significantly by domain structure. $\mathrm{HiCDH} 1$ showed substrate-specific transcript level profiles and appeared to be coordinately regulated with different subgroups of HiGH61 genes, whereas $\mathrm{HiCDH} 2$ appeared not to be significantly transcribed on any substrates (Fig. 5) Interestingly, similar results have been observed for the filamentous ascomycete Neurospora crassa which also have two genes encoding $C D H s$, whereof only one is expressed (Phillips et al. 2011). The expressed $N$. crassa $C D H$ (CDH-1; Uniprot ID Q7RXM0), which has been suggested to be the designated electron donor for the $N$. crassa GH61s, also shares the domain structure of the H. irregulare protein HiCDH1 
(these genes share $\sim 60 \%$ sequence identity). It is possible that HiCDH1 of $H$. irregulare can play a similar role to that of CDH1 from $N$. crassa in biomass degradation. The second $\mathrm{CDH}$ from $\mathrm{H}$. irregulare (HiCDH2) also has a similar domain structure to the second $\mathrm{CDH}$ from $N$. crassa, which only contains one flavin domain and a C-terminal CBM1. Interestingly, neither the $\mathrm{HiCDH} 2$ nor the $\mathrm{N}$. crassa $\mathrm{CDH} 2$ are expressed during fungal growth on cellulose (Fig. 5) (Phillips et al. 2011).

The generally higher transcript levels of GH61 genes on wood substrates in comparison to artificial media (MacDonald et al. 2011) suggest involvement of these genes in degradation of wood fiber lignocelluloses. Differential regulation of GH61 family genes on different substrates also imply specificity of different $G H 61$ polysaccharide oxidases to different types of wood cell-wall compounds and could determine the hosts species specificity of a particular fungi species. The fact that some of the GH61 genes, such as HiGH61A and HiGH61B, showed marked difference in the transcript level between spruce heartwood and pine sapwood may reflect some treespecific differences in the structure or composition of the tracheid cell wall. For natural substrates, the currently employed experimental system should provide artificially accelerated decay conditions due to the involved pulverizing of wood and use of inoculum high in colony forming units. The generally lower transcript levels of HiGH61 genes on spruce reaction zone and pine heartwood compared with spruce heartwood and pine sapwood, respectively, are presumably related to the high concentration of antifungal compounds in spruce reaction zone and pine heartwood (Woodward et al. 1998). For example, in the reaction zone of Norway spruce the fungus is likely to use its ligninolytic repertoire for detoxification of host defense polyphenols as well, this resource allocation affecting negatively the rate of cell wall degradation and exposure of cellulose to enzymatic activity (Yamada 2001).

In summary, there is high diversity among the ten GH61 genes present in $H$. irregulare. Based on the transcript profile patterns on the included natural and defined substrates, these genes could be divided into two groups. The major group consisted of eight genes that showed coordinated gene expression with the included reference cellulolytic and hemicellulolytic GHs and generally high upregulation level on woody substrates in contrast to the defined cellulose medium. This demonstrates the cometabolic nature of lignocellulose degradation. The remaining two GH61s, together with starch and oligosaccharide active reference genes, showed little regulation in comparison with the basal Hagem medium control, and could be involved in degradation of more easily available nonstructural carbohydrates that are particularly important during the initial exploratory colonization phase of host tissue by a microbe. These data suggest that GH61 genes participate in degradation of both the structural and reserve carbohydrates of xylem. Further research on both GH61 genes and proteins are warranted particularly on the highly expressed $H i G H 61 G$ with a widely divergent catalytic site and whether specific GH61s may have a role in breaking the link between cellulose and lignin.

Acknowledgments We thank Åke Olson (Swedish University of Agricultural Sciences) for providing the H. irregulare strain TC-32-1 for study and Mari Kjos (Skogoglandskap) for valuable technical assistance in gene amplification and sequencing. This work was supported by the Norwegian Research Council (grants \#315052 and 135901).

Open Access This article is distributed under the terms of the Creative Commons Attribution License which permits any use, distribution, and reproduction in any medium, provided the original author(s) and the source are credited.

\section{References}

Cantarel BL, Coutinho PM, Rancurel C, Bernard T, Lombard V, Henrissat B (2009) The carbohydrate-active EnZymes database (CAZy): an expert resource for glycogenomics. Nucleic Acids Res 37:D233-D238

Dalman K, Olson Å, Stenlid J (2010) Evolutionary history of the conifer root rot fungus Heterobasidion annosum sensu lato. Mol Ecol 19:4979-4993

DeLano WL (2002) The PyMOL molecular graphics system. DeLano Scientific, San Carlos, CA

Dyrløv Bendtsen J, Nielsen H, von Heijne G, Brunak S (2004) Improved prediction of signal peptides: signalP 3.0. J Mol Biol 340:783-795

Eastwood DC, Floudas D, Binder M, Majcherczyk A, Schneider P, Aerts A, Asiegbu FO, Baker SE, Barry K, Bendiksby M, Blumentritt M, Coutinho PM, Cullen D, de Vries RP, Gathman A, Goodell B, Henrissat B, Ihrmark K, Kauserud H, Kohler A, LaButti K, Lapidus A, Lavin JL, Lee Y-H, Lindquist E, Lilly W, Lucas S, Morin E, Murat C, Oguiza JA, Park J, Pisabarro AG, Riley R, Rosling A, Salamov A, Schmidt O, Schmutz J, Skrede I, Stenlid J, Wiebenga A, Xie X, Kües U, Hibbett DS, Hoffmeister D, Högberg N, Martin F, Grigoriev IV, Watkinson SC (2011) The plant cell wall-decomposing machinery underlies the functional diversity of forest fungi. Science 333:762-765

Eswar N, Webb B, Marti-Renom MA, Madhusudhan MS, Eramian D, Shen M-Y, Pieper U, Sali A (2007) Comparative protein structure modeling using MODELLER. Current protocols in protein science. Wiley, New York

Forsberg Z, Vaaje-Kolstad G, Westereng B, Bunaes AC, Stenstrom Y, Mackenzie A, Sorlie M, Horn SJ, Eijsink VGH (2011) Cleavage of cellulose by a CBM33 protein. Protein Sci 20:1479-1483

Gilkes NR, Henrissat B, Kilburn DG, Miller RC Jr, Warren RA (1991) Domains in microbial $\beta$-1,4-glycanases: sequence conservation, function, and enzyme families. Microbiol Rev 55:303-315

Goodell B, Jellison J, Liu J, Daniel G, Paszczynski A, Fekete F, Krishnamurthy S, Jun L, Xu G (1997) Low molecular weight chelators and phenolic compounds isolated from wood decay fungi and their role in the fungal biodegradation of wood. J Biotechnol 53:133-162

Harris PV, Welner D, McFarland KC, Re E, Navarro Poulsen J-C, Brown K, Salbo R, Ding H, Vlasenko E, Merino S, Xu F, Cherry J, Larsen S, Lo Leggio L (2010) Stimulation of lignocellulosic 
biomass hydrolysis by proteins of glycoside hydrolase family 61 : structure and function of a large, enigmatic family. Biochemistry 49:3305-3316

Karkehabadi S, Hansson H, Kim S, Piens K, Mitchinson C, Sandgren M (2008) The first structure of a glycoside hydrolase family 61 member, Cel61B from Hypocrea jecorina, at $1.6 \AA$ resolution. J Mol Biol 383:144-154

Langston JA, Shaghasi T, Abbate E, Xu F, Vlasenko E, Sweeney MD (2011) Oxidoreductive cellulose depolymerization by the enzymes cellobiose dehydrogenase and glycoside hydrolase 61 . Appl Environ Microbiol 77:7007-7015

Laskowski RA, MacArthur MW, Moss DS, Thornton JM (1993) PROCHECK: a program to check the stereochemical quality of protein structures. J App Cryst 26:283-291

Longoni P, Rodolfi M, Pantaleoni L, Doria E, Concia L, Picco AM, Cella R (2012) Degradation of cellulosic substrates by a Chaetomium globosum endophytic isolate: a functional analysis. Appl Environ Microbiol 78:3693-3705. doi:10.1128/ AEM.00124-12

MacDonald J, Doering M, Canam T, Gong Y, Guttman DS, Campbell MM, Master ER (2011) Transcriptomic responses of the softwood-degrading white-rot fungus Phanerochaete carnosa during growth on coniferous and deciduous wood. Appl Environ Microbiol 77:3211-3218

Marchler-Bauer A, Lu S, Anderson JB, Chitsaz F, Derbyshire MK, DeWeese-Scott C, Fong JH, Geer LY, Geer RC, Gonzales NR, Gwadz M, Hurwitz DI, Jackson JD, Ke Z, Lanczycki CJ, Lu F, Marchler GH, Mullokandov M, Omelchenko MV, Robertson CL, Song JS, Thanki N, Yamashita RA, Zhang D, Zhang N, Zheng C, Bryant SH (2011) CDD: a conserved domain database for the functional annotation of proteins. Nucleic Acids Res 39:D225-D229

Mason MG, Nicholls P, Wilson MT (2003) Rotting by radicals the role of cellobiose oxidoreductase? Biochem Soc Trans 31:1335-1336

Merino S, Cherry J (2007) Progress and challenges in enzyme development for biomass utilization. In: Olsson L (ed) Biofuels. Advances in Biochemical Engineering/Biotechnology. Springer, Berlin, pp 95-120

Niemelä T, Korhonen K (1998) Taxonomy of the genus Heterobasidion. In: Woodward S, Stenlid O, Karjalainen K, Hüttermann A (eds) Heterobasidion annosum: biology, ecology, impact and control. CAB International, London, pp 27-33

Notredame C, Higgins DG, Heringa J (2000) T-coffee: a novel method for fast and accurate multiple sequence alignment. J Mol Biol 302:205-217

Olson Å, Aerts A, Asiegbu F, Belbahri L, Bouzid O, Broberg A, Canbäck B, Coutinho PM, Cullen D, Dalman K, Deflorio G, van Diepen LTA, Dunand C, Duplessis S, Durling M, Gonthier P, Grimwood J, Fossdal CG, Hansson D, Henrissat B, Hietala A, Himmelstrand K, Hoffmeister D, Högberg N, James TY, Karlsson M, Kohler A, Kües U, Lee Y-H, Lin Y-C, Lind M, Lindquist E, Lombard V, Lucas S, Lundén K, Morin E, Murat C, Park J, Raffaello T, Rouzé P, Salamov A, Schmutz J, Solheim H, Ståhlberg J, Vélëz H, de Vries RP, Wiebenga A, Woodward S, Yakovlev I, Garbelotto M, Martin F, Grigoriev IV, Stenlid J (2012) Insight into trade-off between wood decay and parasitism from the genome of a fungal forest pathogen. New Phytol 194:1001-1013

Otrosina WJ, Garbelotto M (2010) Heterobasidion occidentale sp. nov. and Heterobasidion irregulare nom. nov.: A disposition of North
American Heterobasidion biological species. Fungal Biol 114:16-25

Phillips CM, Beeson WT, Cate JH, Marletta MA (2011) Cellobiose dehydrogenase and acopper-dependent polysaccharide monooxygenase potentiate cellulose degradation by Neurospora crassa. ACS Chem Biol 6:1399-1406

Quinlan RJ, Sweeney MD, Lo Leggio L, Otten H, Poulsen J-CN, Johansen KS, Krogh KBRM, Jørgensen CI, Tovborg M, Anthonsen A, Tryfona T, Walter CP, Dupree P, Xu F, Davies GJ, Walton $\mathrm{PH}$ (2011) Insights into the oxidative degradation of cellulose by a copper metalloenzyme that exploits biomass components. Proc Natl Acad Sci USA 108:15079-15084

Reese ET, Siu RGH, Levinson HS (1950) The biological degradation of soluble cellulose derivatives and its relationship to the mechanism of cellulose hydrolysis. J Bacteriol 59:485-497

Rozen S, Skaletsky HJ (2000) Primer3 on the WWW for general users and for biologist programmers. In: Krawetz S, Misener S (eds) Methods in molecular biology. Humana Press, Totowa, pp 365-386

Tamura K, Peterson D, Peterson N, Stecher G, Nei M, Kumar S (2011) MEGA5: molecular evolutionary genetics analysis using maximum likelihood, evolutionary distance, and maximum parsimony methods. Mol Biol Evol 28:2731-2739

Teeri TT (1997) Crystalline cellulose degradation: new insight into the function of cellobiohydrolases. Trends Biotechnol 15:160-167

Vaaje-Kolstad G, Horn SJ, van Aalten DMF, Synstad B, Eijsink VGH (2005a) The non-catalytic chitin-binding protein CBP21 from Serratia marcescens is essential for chitin degradation. J Biol Chem 280:28492-28497

Vaaje-Kolstad G, Houston DR, Riemen AHK, Eijsink VGH, van Aalten DMF (2005b) Crystal structure and binding properties of the Serratia marcescens chitin-binding protein CBP21. J Biol Chem 280:11313-11319

Vaaje-Kolstad G, Westereng B, Horn SJ, Liu Z, Zhai H, Sørlie M, Eijsink VGH (2010) An oxidative enzyme boosting the enzymatic conversion of recalcitrant polysaccharides. Science 330:219-222

Vriend G (1990) WHAT IF: a molecular modeling and drug design program. J Mol Graphics 8:52-56

Westereng B, Ishida T, Vaaje-Kolstad G, Wu M, Eijsink VGH, Igarashi K, Samejima M, Ståhlberg J, Horn SJ, Sandgren M (2011) The putative endoglucanase PcGH61d from Phanerochaete chrysosporium is a metal-dependent oxidative enzyme that cleaves cellulose. PLoS One 6:e27807

Wiederstein M, Sippl MJ (2007) ProSA-web: interactive web service for the recognition of errors in three-dimensional structures of proteins. Nucleic Acids Res 35:W407-W410

Woodward S, Stenlid J, Karjalainen R, Hüttermann A (1998) Heterobasidion annosum. Biology, ecology, impact and control. $\mathrm{CAB}$ International, Cambridge

Yakovlev IA, Hietala AM, Steffenrem A, Solheim H, Fossdal CG (2008) Identification and analysis of differentially expressed Heterobasidion parviporum genes during natural colonization of Norway spruce stems. Fungal Genet Biol 45:498-513

Yamada T (2001) Defense mechanisms in the sapwood of living trees against microbial infection. J For Res 6:127-137

Zamocky M, Ludwig R, Peterbauer C, Hallberg BM, Divne C, Nicholls P, Haltrich D (2006) Cellobiose dehydrogenase - a flavocytochrome from wood-degrading, phytopathogenic and saprotropic fungi. Curr Protein Peptide Sci 7:255-280 